\title{
O ensino de transformações geométricas: uma síntese da literatura envolvendo tarefas e a prática do professor
}

\author{
Geometric transformations teaching: a literature synthesis \\ involving tasks and the teacher's practice
}

\author{
Natalia Nascimben Delmondi ${ }^{1}$ \\ Vinícius Pazuch ${ }^{2}$
}

\section{RESUMO}

Esse artigo tem como objetivo apresentar uma síntese da literatura acerca do ensino do conteúdo matemático de transformações geométricas, contemplando dois aspectos em relação ao tema: prática do professor e tarefas. Assim, as questões norteadoras deste trabalho foram: que perfil apresentam as pesquisas em Educação Matemática que tratam da prática do professor? e qual a natureza das tarefas elaboradas para abordar as transformações geométricas na prática em sala de aula? Para responder tais questões, foram selecionados 16 artigos publicados em revistas brasileiras da área de Ensino, classificadas com os Qualis A1, A2 e B1, no portal WebQualis CAPES, no quadriênio 2013. 2016. A análise desses artigos evidenciou que (i) são pesquisas empíricas, que possuem como focos de análise a formação continuada, a formação inicial e os conhecimentos do professor; e (ii) a natureza das tarefas presentes nos artigos que tratam das transformações geométricas foi diversa: exercícios, problemas, explorações e investigações, com predomínio dos primeiros e das últimas, e correlação entre as demandas cognitivas da tarefa e a progressão do conteúdo. Com base nesse estudo, constataram-se lacunas no conhecimento do professor e a carência de maior diversidade tanto nas tarefas acerca do conteúdo matemático de transformações geométricas, aplicadas a propósitos variados, quanto nas habilidades do professor para adequá-las de acordo com os seus

1. Mestranda em Ensino e História das Ciências e da Matemática. Graduada em Ciência e Tecnologia pela Universidade Federal do ABC (UFABC), Santo André (SP), Brasil. E-mail: natalia_delmondi@yahoo.com.br

2. Professor Adjunto do Centro de Matemática, Computação e Cognição da Universidade Federal do ABC (UFABC), Santo André (SP), Brasil. E-mail: vinicius.pazuch@ufabc.edu.br 
objetivos. Tais aspectos podem ser minimizados por meio de processos de formação continuada que explorem esses temas.

Palavras-chave: Ensino de Geometria; Natureza das Tarefas; Artigos Científicos.

\begin{abstract}
This article aims to present a literature synthesis about the teaching of the mathematical content, geometric transformations, contemplating two aspects in relation to the theme: teacher's practice and tasks. Thus, the guiding questions of this work were: (i) What profile do the studies on Mathematics Education that deal with the teacher's practice present? and (ii) What is the nature of the tasks designed to address geometric transformations in classroom practice? To answer these questions, 16 articles published in Brazilian journals in the area of Education were selected, classified as Qualis A1, A2 and B1, through the WebQualis CAPES portal, in the 2013-2016 quadrennium. The analysis of these articles showed that (i) they are empirical studies, which have continuing education, initial education and the teacher's knowledge as focus of analysis, and (ii) the nature of the tasks present in the articles dealing with geometric transformations was diverse, some of which were: exercises, problems, explorations and investigations being observed, with predominance in the first and last, respectively, and the correlation between the cognitive demands of the task and the content progression. Based on this, gaps were found in the teacher's knowledge, and in the lack of greater diversity in the tasks concerning the mathematical content of geometric transformations, applied for various purposes, as well as in the teacher's ability to adapt them to their objectives. Such aspects can be minimized through continuing education processes that explore these themes.
\end{abstract}

Keywords: The Teaching of Geometry; The Nature of Tasks; Scientific articles.

\title{
1. Introdução
}

Neste artigo, exporemos uma síntese da literatura envolvendo o ensino de transformações geométricas, a natureza de tarefas e a atuação do professor em sala de aula. A temática das transformações geométricas é discutida em pesquisas atuais no cenário nacional e internacional. Esse tratamento acontece por meio de revisão da literatura (DELMONDI; PAZUCH, 2018), da análise de materiais curriculares (DELMONDI; PAZUCH, 2019), em processos de ensino e de aprendizagem (LOPES; 
ALVES; FERREIRA, 2015; NG; SINCLAIR, 2015) e de formação de professores (MAIA, 2014; SANTOS; BICUDO, 2015).

Adotamos a definição de Wagner (2007) de transformações geométricas, consistindo em um tópico específico da geometria que trata de alterações no posicionamento (transformações isométricas: translações, reflexões, e rotações, que podem ocorrer em relação a um ponto ou a um eixo de simetria) ou nas dimensões (homotetias) de uma dada figura, em relação a uma figura inicial. A contribuição do ensino de transformações geométricas para os processos de ensino e de aprendizagem transcende a compreensão dos conceitos matemáticos no âmbito escolar. Por exemplo, as transformações geométricas contribuem para o desenvolvimento das atividades de arte, arquitetura, engenharia, bem como de outras áreas do conhecimento.

No âmbito escolar, destacam-se as tarefas, consideradas como materiais didáticos produzidos pelo professor, que têm como centralidade impulsionar o processo de elaboração conceitual pelos estudantes e, por conseguinte, a aprendizagem matemática. Tomamos como referência Ponte (2014) para abordar as tipologias das tarefas: exercício, problema, exploração e investigação.

Uma das ações docentes é a própria prática. Para além das tarefas que coparticipam do planejamento do professor, na sua prática docente ou na sua atuação, outros aspectos são mobilizados. Podemos dizer que crenças, conhecimentos, concepções se movimentam quando o professor planeja, executa e reflete sobre as aulas (de matemática).

Considerando a relevância das tarefas e da prática docente, elaboramos duas questões norteadoras deste artigo: Que perfil apresentam as pesquisas em Educação Matemática que tratam da prática do professor? Qual a natureza das tarefas elaboradas para abordar as transformações geométricas na prática em sala de aula? $\mathrm{Na}$ sequência, apresentaremos os procedimentos metodológicos, a descrição e a análise dos resultados. Por fim, as considerações finais e as perspectivas futuras, decorrentes da síntese da literatura.

\section{Procedimentos metodológicos}

Para a realização desta pesquisa, foram consultadas revistas brasileiras da área de Ensino, classificadas com os Qualis A1, A2 e B1, 
no portal WebQualis CAPES, no quadriênio 2013-2016. Nas revistas, foram consultados os seguintes descritores: geometria, isometria, transformações geométricas, transformações isométricas, simetria. Essa consulta inicial resultou em um total de 714 artigos encontrados.

Foram analisados seus títulos, seus resumos e as palavras-chave, para verificar se eles tratavam de Transformações Geométricas e Prática do Professor, ou Transformações Geométricas e Tarefas. Para essa seleção, consideramos como prática do professor discussões de tópicos como o conhecimento e a atuação docente, seja ela na formação inicial ou continuada desses profissionais. Já a elaboração de tarefas foi entendida como proposta de tarefas apresentadas nos artigos, concebidas pelos pesquisadores/autores dos artigos, ou por professores em exercício que compuseram as suas pesquisas, culminando ou não na aplicação de tais tarefas para um grupo de estudantes. Assim, apenas com esta análise, o número de artigos foi reduzido para 16, sendo este o total de artigos que compuseram essa revisão sistemática de literatura (Quadro 1). Desses textos, sete envolvem a prática do professor, e nove tratam da elaboração de tarefas.

Quadro 1. Artigos Selecionados

\begin{tabular}{|c|c|c|c|c|}
\hline Revista & Tema & Descritor & Título do Artigo & Autores \\
\hline $\begin{array}{c}\text { Educação } \\
\text { Matemática } \\
\text { Pesquisa }\end{array}$ & $\begin{array}{c}\text { Prática do } \\
\text { professor }\end{array}$ & Simetria & $\begin{array}{c}\text { "Conhecimentos e } \\
\text { concepções de professores de } \\
\text { matemática: análise de } \\
\text { sequências didáticas" }\end{array}$ & Lima (2011) \\
\hline $\begin{array}{l}\text { Ciência \& } \\
\text { Educação }\end{array}$ & $\begin{array}{c}\text { Prática do } \\
\text { professor }\end{array}$ & Geometria & $\begin{array}{c}\text { "Geometria Dinâmica na } \\
\text { Sala de Aula: o } \\
\text { Desenvolvimento do Futuro } \\
\text { Professor de Matemática } \\
\text { Diante da Imprevisibilidade" }\end{array}$ & $\begin{array}{c}\text { Silva e } \\
\text { Penteado } \\
(2013)\end{array}$ \\
\hline REVEMAT & $\begin{array}{c}\text { Prática do } \\
\text { Professor }\end{array}$ & Geometria & $\begin{array}{l}\text { "Conhecimento de geometria } \\
\text { e perspectivas de professores } \\
\text { do } 1^{\circ} \text { ciclo do ensino básico } \\
\text { sobre o seu ensino" }\end{array}$ & $\begin{array}{l}\text { Viseu, } \\
\text { Menezes e } \\
\text { Almeida } \\
(2013)\end{array}$ \\
\hline Bolema & $\begin{array}{c}\text { Prática do } \\
\text { professor }\end{array}$ & Simetria & $\begin{array}{l}\text { "Symmetry and Rotation } \\
\text { Skills of Prospective } \\
\text { Elementary Mathematics } \\
\text { Teachers" }\end{array}$ & $\begin{array}{c}\text { Turgut, } \\
\text { Yenilmez e } \\
\text { Anapa (2014) }\end{array}$ \\
\hline Bolema & $\begin{array}{c}\text { Prática do } \\
\text { professor }\end{array}$ & $\begin{array}{l}\text { Geometria } \\
\text { Transfor- } \\
\text { mações } \\
\text { Geomé- } \\
\text { tricas }\end{array}$ & $\begin{array}{c}\text { "Uma Experiência de } \\
\text { Formação Continuada com } \\
\text { Professores de Arte e } \\
\text { Matemática no Ensino de } \\
\text { Geometria" }\end{array}$ & $\begin{array}{c}\text { Santos e } \\
\text { Bicudo (2015) }\end{array}$ \\
\hline
\end{tabular}




\begin{tabular}{|c|c|c|c|c|}
\hline $\begin{array}{c}\text { Acta } \\
\text { Scientiae }\end{array}$ & $\begin{array}{l}\text { Prática do } \\
\text { professor }\end{array}$ & Simetria & $\begin{array}{l}\text { "Uma articulação entre o } \\
\text { quadro dos Paradigmas } \\
\text { Geométricos e a Teoria das } \\
\text { Situações Didáticas" }\end{array}$ & $\begin{array}{c}\text { Silva e } \\
\text { Almouloud } \\
(2018) \\
\text {. }\end{array}$ \\
\hline $\begin{array}{c}\text { Educação } \\
\text { Matemática } \\
\text { Pesquisa }\end{array}$ & $\begin{array}{l}\text { Prática do } \\
\text { professor }\end{array}$ & Geometria & $\begin{array}{c}\text { "Estratégias didáticas com } \\
\text { tecnologias na formação } \\
\text { continuada de professores de } \\
\text { Matemática: uma } \\
\text { investigação sobre } \\
\text { homotetia" } \\
\end{array}$ & $\begin{array}{c}\text { Oliveira e } \\
\text { Lima (2018) }\end{array}$ \\
\hline $\begin{array}{l}\text { Boletim } \\
\text { GEPEM }\end{array}$ & $\begin{array}{l}\text { Elaboração de } \\
\text { tarefas }\end{array}$ & Simetria & $\begin{array}{c}\text { "Translações e Simetrias no } \\
\text { plano" }\end{array}$ & $\begin{array}{l}\text { Fainguelernt e } \\
\text { Bordinhão } \\
(1990)\end{array}$ \\
\hline Zetetiké & $\begin{array}{l}\text { Elaboração de } \\
\text { tarefas }\end{array}$ & $\begin{array}{l}\text { Geometria } \\
\text { Simetria }\end{array}$ & $\begin{array}{c}\text { "Uma Aplicação do Conceito } \\
\text { de Simetria Axial Plana } \\
\text { Visando a um Ensino } \\
\text { Interdisciplinar" }\end{array}$ & Kaleff (1994) \\
\hline $\begin{array}{l}\text { Educação } \\
\text { Matemática } \\
\text { em Revista }\end{array}$ & $\begin{array}{l}\text { Elaboração de } \\
\text { tarefas }\end{array}$ & Geometria & $\begin{array}{l}\text { "Ornamentos versus } \\
\text { Criatividade: uma alternativa } \\
\text { para ensinar geometria plana } \\
\text { e simetria" }\end{array}$ & $\begin{array}{c}\text { Biembengut e } \\
\text { Silva (1995) }\end{array}$ \\
\hline $\begin{array}{l}\text { Boletim } \\
\text { GEPEM }\end{array}$ & $\begin{array}{l}\text { Elaboração de } \\
\text { tarefas }\end{array}$ & Simetria & $\begin{array}{l}\text { "Construindo o conceito de } \\
\text { simetria em relação a uma } \\
\text { reta: do jardim de infância ao } \\
3^{\circ} \text { grau" }\end{array}$ & Kaleff (1999) \\
\hline Bolema & $\begin{array}{l}\text { Elaboração de } \\
\text { tarefas }\end{array}$ & $\begin{array}{l}\text { Geometria } \\
\text { Isometria } \\
\text { Transfor- } \\
\text { mações } \\
\text { Geomé- } \\
\text { tricas } \\
\end{array}$ & $\begin{array}{c}\text { "O Uso de Espelhos e } \\
\text { Caleidoscópios em } \\
\text { Atividades Educacionais de } \\
\text { Geometria para } 7^{\mathrm{a}} \text { e } 8^{\mathrm{a}} \text { séries" }\end{array}$ & $\begin{array}{c}\text { Murari e } \\
\text { Perez }(2002)\end{array}$ \\
\hline $\begin{array}{l}\text { Boletim } \\
\text { GEPEM }\end{array}$ & $\begin{array}{l}\text { Elaboração de } \\
\text { tarefas }\end{array}$ & Geometria & $\begin{array}{c}\text { "Exploração de trabalhos de } \\
\text { Escher em aulas de } \\
\text { geometria" }\end{array}$ & $\begin{array}{l}\text { Nina, } \\
\text { Menegassi e } \\
\text { Silva (2008) }\end{array}$ \\
\hline Bolema & $\begin{array}{l}\text { Elaboração de } \\
\text { tarefas }\end{array}$ & $\begin{array}{l}\text { Simetria } \\
\text { Isometria } \\
\text { Transfor- } \\
\text { mações } \\
\text { Geomé- } \\
\text { tricas } \\
\end{array}$ & $\begin{array}{l}\text { "Simetria no Ensino } \\
\text { Fundamental através da } \\
\text { Resolução de Problemas: } \\
\text { possibilidades para um } \\
\text { trabalho em sala de aula" }\end{array}$ & $\begin{array}{c}\text { Vieira, Paulo } \\
\text { e Allevato } \\
(2013)\end{array}$ \\
\hline $\begin{array}{l}\text { Educação e } \\
\text { Realidade }\end{array}$ & $\begin{array}{l}\text { Elaboração de } \\
\text { tarefas }\end{array}$ & Simetria & $\begin{array}{l}\text { "A Simetria nas Aulas de } \\
\text { Matemática: uma proposta } \\
\text { investigativa" }\end{array}$ & $\begin{array}{l}\text { Lopes, Alves } \\
\text { e Ferreira } \\
\text { (2015) }\end{array}$ \\
\hline $\begin{array}{l}\text { Boletim } \\
\text { GEPEM }\end{array}$ & $\begin{array}{l}\text { Elaboração de } \\
\text { tarefas }\end{array}$ & $\begin{array}{l}\text { Transfor- } \\
\text { mações } \\
\text { Isométricas }\end{array}$ & $\begin{array}{l}\text { "Transformações isométricas } \\
\text { com manipulações em tela" }\end{array}$ & Assis (2017) \\
\hline
\end{tabular}

Fonte: autores

Esses artigos foram analisados, verificando aspectos como a sua natureza (artigo de pesquisa ou relato de experiência) e o contexto metodológico (teórico ou empírico, com resultados obtidos por meio de 
pesquisas de campo) utilizado nos artigos. Esses aspectos foram definidos a priori, com o propósito de realizar uma reflexão sobre quais dessas características são reveladas em estudos sobre as transformações geométricas, bem como o porquê de tais predominâncias (ou não) delas.

Um artigo de pesquisa apresenta o resultado de um trabalho científico realizado a partir de um questionamento a ser estudado e/ou respondido. Assim,

existem dois momentos fundamentais num processo de investigação: o de formulação do problema, ou da questão de investigação e o de construção das conclusões da pesquisa. Entretanto, para chegar-se a uma conclusão ou a uma resposta consistente e confiável para a questão/pergunta de investigação, precisamos buscar ou construir um caminho (isto é, uma alternativa metodológica mais segura possível) o qual permita, de maneira satisfatória, tratar o problema ou responder a questão de investigação. (FIORENTINI; LORENZATO, 2006, p. 60, grifos dos autores)

A Figura 1 exemplifica a estrutura de uma investigação que pode resultar em um artigo de pesquisa:

Figura 1. Estrutura de uma Investigação

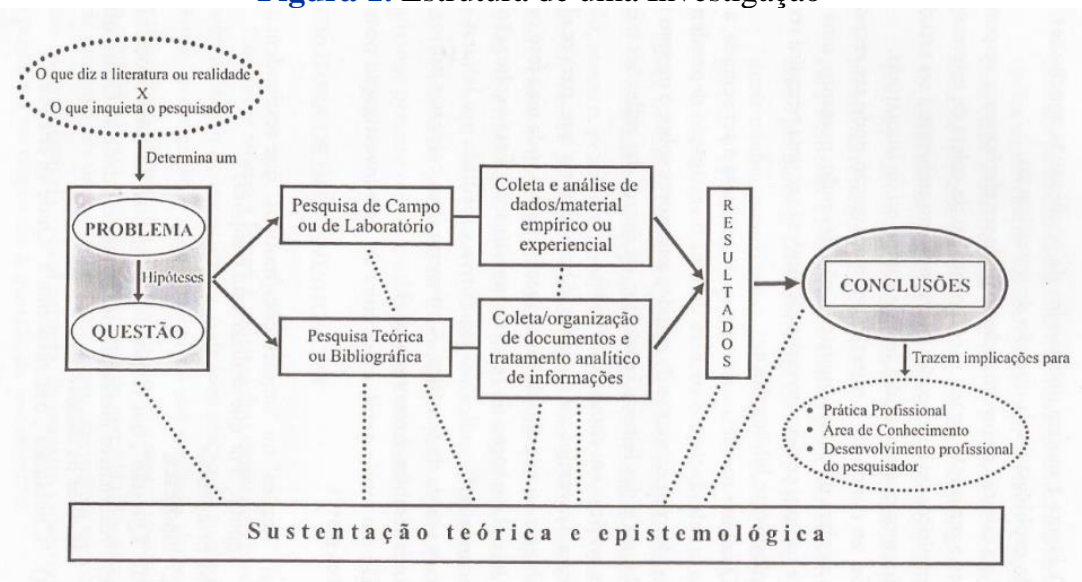

Fonte: FIORENTINI; LORENZATO, 2006, p. 62 
Um relato de experiência pode ser tratado como um espaço para narrar vivências ou ações de sala de aula, em que a natureza da atividade prática se destaca por suas questões teóricas e epistemológicas.

Com relação aos artigos que tratam da prática do professor, após as leituras, foi possível constatar a presença de três enfoques: aqueles que tratam da formação inicial, da formação continuada ou do conhecimento do professor sobre o conteúdo de transformações geométricas. A partir desses enfoques, tais artigos foram analisados por meio dos critérios estabelecidos por Pazuch e Ribeiro (2017, p. 482, grifos dos autores), incluindo os seguintes aspectos:

a) Questões de investigação ou objetivos: tratam dos propósitos a serem atingidos pelos autores com suas respectivas propostas de pesquisa.

b) Procedimentos metodológicos: mostram "a natureza da pesquisa, os instrumentos de coleta/produção de dados, as escolhas analíticas e o cenário de investigação".

c) Resultados: apresentam as conclusões obtidas a partir das questões de investigação e/ou objetivos estabelecidos pelas referidas pesquisas.

Esses critérios foram selecionados por permitirem uma reflexão acerca dos conteúdos abordados nas pesquisas sobre transformações geométricas, bem como explorando os resultados apresentados nelas, a fim de fomentar novas pesquisas sobre esse tema.

Também foram observados, nos artigos que tratam da prática do professor, os principais referenciais teóricos utilizados por seus autores, a fim de pontuar quais linhas de pesquisa são mais frequentes nesta temática de pesquisa.

Os artigos que tratam da elaboração de tarefas foram classificados de acordo com os tipos de tarefas propostas por eles, segundo Ponte (2014, p. 21, grifos do autor), em que "um exercício é uma tarefa fechada e de desafio reduzido; Um problema é uma tarefa também fechada, mas com desafio elevado; Uma investigação é uma tarefa aberta com desafio elevado; Uma exploração é uma tarefa aberta e acessível à maioria dos alunos". A escolha de tais categorias, realizada antes da leitura dos artigos, se deu com o intuito de discutirmos sobre qual(is) dela(s) são mais evidentes no ensino das transformações geométricas. Também, 
indicamos em que elas são utilizadas (como por exemplo, introduzir ou consolidar o conteúdo desejado). Após essa classificação, apresentaremos uma tarefa de cada um desses tipos, extraídas dos artigos analisados, a fim de exemplificar e justificar a classificação das tarefas realizadas. Os dados resultantes dessas análises serão reportados a seguir.

\section{Apresentação e análise dos dados}

\subsection{Prática do Professor}

Após a análise dos títulos e dos resumos dos artigos selecionados, algumas de suas características puderam ser pontuadas. A primeira delas é que todos os artigos analisados apresentaram pesquisas empíricas, ou seja, todos obtiveram seus resultados a partir de dados produzidos em pesquisas de campo. Essa característica mostra que as pesquisas sobre a prática docente estão sendo desenvolvidas, aplicadas e validadas, visando enaltecer o conhecimento e a identidade profissional do professor em exercício.

Com relação à sua natureza, todos os trabalhos sobre a prática do professor são artigos de pesquisa. Embora tenham obtido seus resultados a partir de uma vivência e/ou experiência, nenhum deles se limitou a compreender apenas o fenômeno da experiência, pois expuseram seus embasamentos teóricos para justificar a realização da pesquisa e responderam a seus objetivos e questões de pesquisa em consonância com as escolhas metodológicas.

O último aspecto identificado nesta primeira análise diz respeito às unidades analíticas consideradas para olhar a prática do professor nos artigos selecionados. Três unidades foram identificadas: a formação inicial, a formação continuada e o conhecimento do professor. Os resultados dessa análise estão apresentados no Quadro 2: 
Quadro 2. Perfil dos artigos que tratam da prática do professor

\begin{tabular}{|c|c|c|c|}
\hline Autor & $\begin{array}{l}\text { Formação } \\
\text { Inicial }\end{array}$ & $\begin{array}{c}\text { Formação } \\
\text { Continuada }\end{array}$ & $\begin{array}{c}\text { Conhecimento do } \\
\text { Professor }\end{array}$ \\
\hline Lima (2011) & & & $\mathrm{x}$ \\
\hline $\begin{array}{l}\text { Silva e } \\
\text { Penteado } \\
\text { (2013) }\end{array}$ & $\mathrm{x}$ & & \\
\hline $\begin{array}{l}\text { Viseu, Menezes } \\
\text { e Almeida } \\
\text { (2013) }\end{array}$ & & & $\mathrm{x}$ \\
\hline $\begin{array}{c}\text { Turgut, } \\
\text { Yenilmez e } \\
\text { Anapa (2014) }\end{array}$ & $\mathrm{x}$ & & \\
\hline $\begin{array}{c}\text { Santos e Bicudo } \\
\text { (2015) }\end{array}$ & & $\mathrm{x}$ & \\
\hline $\begin{array}{c}\text { Silva e } \\
\text { Almouloud } \\
(2018)\end{array}$ & & & $\mathrm{x}$ \\
\hline $\begin{array}{c}\text { Oliveira e Lima } \\
\text { (2018) }\end{array}$ & & $\mathrm{x}$ & \\
\hline
\end{tabular}

Portanto, com relação às unidades analíticas direcionadas à pratica do professor, podemos observar que, nos artigos analisados, há um equilíbrio entre o número de artigos que tratam da formação inicial, da formação continuada e do conhecimento do professor, evidenciando a necessidade e a relevância do estudo de cada uma dessas vertentes. A seguir, apresentaremos a descrição e a análise, de acordo com o enfoque de cada um dos artigos constantes no Quadro 2.

\subsubsection{Formação Inicial}

Dois dos artigos selecionados abordaram a formação inicial do professor que ensina transformações geométricas: os trabalhos de Silva e Penteado (2013) e de Turgut, Yenilmez e Anapa (2014), ambos realizados a partir da verificação e da aplicação do conhecimento que os futuros professores possuíam sobre as transformações geométricas, tendo, porém, utilizado recursos distintos.

Silva e Penteado (2013) optaram por analisar como os professores em formação eram capazes de articular conhecimentos de transformações geométricas com seus estudantes a partir do uso de softwares de geometria dinâmica, lidando com as possiveis imprevisibilidades que poderiam surgir durante o trabalho. Os resultados mostraram que o trabalho favoreceu a aprendizagem dos 
futuros professores, que, além das experiências adquiridas ao lidar com situações que não haviam sido previstas previamente, familiarizaram-se com outras ferramentas, como softwares de geometria dinâmica, que podem ser utilizadas para o ensino das transformações geométricas.

Já Turgut, Yenilmez e Anapa (2014) optaram por verificar, de uma maneira mais direta, o conhecimento de professores em formação sobre os conteúdos de transformações geométricas de simetria e rotação, através de um estudo de caso. Após a aplicação, aos futuros professores, de tarefas que abordassem tais conteúdos, os autores constataram: que os professores em formação têm facilidade em desenhar o correspondente simétrico de uma figura de acordo com o eixo dado, mas possuem dificuldade em encontrar eixos de simetria; e que os futuros professores possuem um conhecimento superficial sobre o conteúdo de rotações.

\subsubsection{Formação Continuada}

Assim como no tópico anterior, também a formação continuada de professores foi objeto de dois artigos analisados.

O primeiro deles, de Santos e Bicudo (2015), visou analisar as estratégias utilizadas por professores em exercício, que compunham um grupo de estudo em um curso de formação continuada, utilizaram as transformações geométricas para solucionar tarefas que abordassem as pavimentações num plano. Os autores observaram que as discussões em grupos de estudo potencializaram o trabalho desenvolvido e a construção do conhecimento pelos professores.

O outro artigo, de Oliveira e Lima (2018), teve como objetivo apresentar estratégias didáticas para um grupo de professores participantes de ações de formação continuada, que pudessem potencializar o conhecimento deles em homotetias. Após a apresentação, a familiarização e a discussão de tais estratégias, os autores constataram que os professores em exercício realizaram progresso com relação ao conhecimento sobre o conteúdo de homotetias. 


\subsubsection{Conhecimento do Professor}

Dentre os sete artigos abordados neste trabalho, que tratam da prática do professor, três são direcionados para o conhecimento que os professores possuem sobre o conteúdo de transformações geométricas. São eles os trabalhos de Lima (2011), Viseu, Menezes e Almeida (2013) e Silva e Almouloud (2018), que serão apresentados a seguir.

O artigo de Lima (2011) tem como objetivo analisar que conhecimentos os professores franceses possuem e mobilizam, e como eles selecionam, articulam e organizam tais conhecimentos para a elaboração de sequências didáticas que abordem o conceito de simetria de reflexão, desde o planejamento das aulas até a sua aplicação. Ainda, o autor pretendia verificar que reflexos tais escolhas didáticas podem causar na aprendizagem dos estudantes. Como resultado, constatou-se que as escolhas didáticas dos professores foram pautadas no seu conhecimento prévio: dos estudantes, do programa escolar e de simetria. Embora os professores tivessem iniciado a elaboração de suas aulas de um mesmo ponto de partida, as sequências didáticas propostas foram diferentes, ora visando desenvolver o conhecimento já apresentado pelo aluno, ora considerando os erros e retomando os conceitos desde o início, mostrando que existem vários meios para se chegar a um mesmo objetivo e que a escolha desses meios será influenciada por fatores como o conhecimento e as preferências do professor e dos estudantes.

Já Viseu, Menezes e Almeida (2013) buscaram analisar o nível de conhecimento de professores portugueses do $1 .^{\circ}$ ciclo do ensino básico sobre o conteúdo de transformações geométricas, e com que relevância esse conteúdo é tratado pelos professores com seus estudantes. Após a aplicação de um questionário aos professores, os autores concluíram que os docentes possuíam dificuldades acentuadas em tópicos de transformações geométricas e que tais dificuldades refletiam na maneira como esse conteúdo era abordado com seus estudantes. Assim, as transformações geométricas, quando trabalhadas em sala de aula, eram abordadas superficialmente e através da repetição de tarefas simples, que não eram capazes de potencializar a aprendizagem dos estudantes sobre o tema.

Por fim, Silva e Almouloud (2018) optaram por apresentar uma metodologia de análise sobre como as ações, conhecimentos, atitudes e escolhas didáticas dos professores interferem, positiva ou 
negativamente, no desenvolvimento dos estudantes durante a resolução de tarefas de transformações geométricas, e exemplificar como tal metodologia pode ser utilizada. Ou seja, tal metodologia procura mensurar como se dão os processos de ensino e aprendizagem do conteúdo de transformações geométricas. A metodologia apresentada se mostrou satisfatória para os propósitos desejados.

\subsubsection{Referencial Teórico}

O último aspecto analisado nos artigos que tratam da prática do professor foi o referencial teórico utilizado pelos autores. O Quadro 3 apresenta tais referenciais, bem como as linhas de pesquisa de cada um deles.

Quadro 3. Principais linhas de pesquisa utilizadas como referencial teórico nos artigos

\begin{tabular}{|c|c|c|}
\hline Artigo & Referenciais Teóricos & Linhas de Pesquisa \\
\hline Silva e Penteado (2013) & $\begin{array}{l}\text { 1. Denzin, N. K. e } \\
\text { Lincoln, Y. S. } \\
\text { 2. Penteado, M. G. } \\
\text { 3. Skovsmose, O. }\end{array}$ & $\begin{array}{l}\text { 1. Metodologia de Pesquisa } \\
\text { Qualitativa } \\
\text { 2. Geometria Dinâmica, } \\
\text { Formação de Professores } \\
\text { 3. Educação Matemática Crítica }\end{array}$ \\
\hline $\begin{array}{l}\text { Turgut, Yenilmez e Anapa } \\
\text { (2014) }\end{array}$ & $\begin{array}{l}\text { 1. Dixon, J. K. } \\
\text { 2. Yildirim, K. }\end{array}$ & $\begin{array}{l}\text { 1. Formação de Professores } \\
\text { 2. Metodologia de Pesquisa } \\
\text { Qualitativa }\end{array}$ \\
\hline Santos e Bicudo (2015) & $\begin{array}{l}\text { 1. Santos, M. R. } \\
\text { 2. Bicudo, M. A. V. } \\
\text { 3. Murari, C. }\end{array}$ & $\begin{array}{l}\text { 1. Formação de Professores, } \\
\text { Ensino de Geometria } \\
\text { 2. Fenomenologia no ensino de } \\
\text { Matemática } \\
\text { 3. Ensino-aprendizagem de } \\
\text { Geometria }\end{array}$ \\
\hline Oliveira e Lima (2018) & $\begin{array}{l}\text { 1. Lévy, P. } \\
\text { 2. Borba, M. C. e } \\
\text { Villarreal, M. E. } \\
\text { 3. Oliveira, G. P. }\end{array}$ & $\begin{array}{l}\text { 1. Tecnologias Digitais } \\
\text { 2. Tecnologias Digitais na } \\
\text { Educação Matemática } \\
\text { 3. Tecnologias Digitais na } \\
\text { Educação Matemática }\end{array}$ \\
\hline Lima (2011) & $\begin{array}{l}\text { 1. Balacheff, M. } \\
\text { 2. Margolinas, C. }\end{array}$ & $\begin{array}{l}\text { 1. Tecnologias Digitais na } \\
\text { Educação Matemática } \\
\text { 2. Metodologia de Análise do } \\
\text { Conhecimento do Professor }\end{array}$ \\
\hline $\begin{array}{l}\text { Viseu, Menezes e Almeida } \\
\text { (2013) }\end{array}$ & $\begin{array}{l}\text { 1. Ball, D. } \\
\text { 2. Menezes, L. } \\
\text { 3. Ponte, J. P. }\end{array}$ & $\begin{array}{l}\text { 1. Formação e Conhecimento do } \\
\text { Professor } \\
\text { 2. Investigação Matemática } \\
\text { 3. Investigação Matemática }\end{array}$ \\
\hline
\end{tabular}




\begin{tabular}{|c|c|c|}
\hline Silva e Almouloud (2018) & $\begin{array}{l}\text { 1. Parzysz, B. } \\
\text { 2. Brousseau, G. } \\
\text { 3. Margolinas, C. }\end{array}$ & $\begin{array}{l}\text { 1. Metodologia de Análise do } \\
\text { Conhecimento do Professor } \\
\text { que ensina Geometria } \\
\text { 2. Teoria das Situações Didáticas } \\
\text { 3. Metodologia de Análise do } \\
\text { Conhecimento do Professor }\end{array}$ \\
\hline
\end{tabular}

Nesse sentido, pontuamos que os principais referenciais teóricos se relacionam ao conhecimento e à formação do professor, ao ensino e à aprendizagem de geometria, ao uso de tecnologias digitais na Educação Matemática e à didática francesa. No próximo tópico, discutiremos a natureza das tarefas utilizadas em sala de aula.

\subsection{Tarefas}

Os itens analisados nos artigos que tratam da formação de professores, descritos anteriormente, também compuseram a análise dos artigos que tratam da elaboração de tarefas, e, da mesma forma, todos eles apresentaram um contexto metodológico empírico, evidenciando novamente a relevância de se aplicar e validar o que foi desenvolvido na teoria, a fim de que a pesquisa possa efetivamente fornecer maiores contribuições para o ensino das transformações geométricas.

No entanto, com relação à abordagem dos artigos, quatro deles Murari e Perez (2002), Nina, Menegassi e Silva (2008), Vieira, Paulo e Allevato (2013), Lopes, Alves e Ferreira (2015) - consistiram em artigos de pesquisa, enquanto os outros cinco: Fainguelernt e Bordinhão (1990), Kaleff (1994), Biembengut e Silva (1995), Kaleff (1999) e Assis (2017) foram apresentados como relatos de experiência. Vale salientar que ambas as abordagens apresentam suas contribuições para os estudos sobre tarefas que tratam das transformações geométricas, quer sejam elaborados a partir de uma questão de pesquisa que visa gerar novas reflexões sobre o tema (artigo de pesquisa), quer contenham tarefas já trabalhadas e os resultados de sua utilização, com base em estudos realizados previamente (relato de experiência).

O Quadro 4 descreve os objetivos a serem atingidos em cada uma das tarefas propostas nos respectivos artigos. 
Quadro 4. Tarefas presentes nos artigos

\begin{tabular}{|c|c|}
\hline Artigo & Tarefa \\
\hline $\begin{array}{c}\text { Translações e simetrias no plano } \\
\text { (FAINGUELERNT; } \\
\text { BORDINHÃO, 1990) }\end{array}$ & $\begin{array}{l}\text { 1) Realizar movimentos com o próprio corpo ou com objetos a } \\
\text { fim de verificar propriedades das translações e simetrias; } \\
\text { identificar que transformações ocorreram em dadas figuras; } \\
\text { realizar as transformações propostas a partir de uma malha } \\
\text { quadriculada. } \\
\text { 2) Identificar transformações geométricas em gráficos. } \\
\text { 3) Associar as transformações geométricas com funções. }\end{array}$ \\
\hline $\begin{array}{l}\text { Uma aplicação do conceito de } \\
\text { simetria axial plana visando a um } \\
\text { ensino interdisciplinar (KALEFF, } \\
\text { 1994) }\end{array}$ & $\begin{array}{l}\text { 1) Encontrar o eixo de simetria em determinadas figuras. } \\
\text { 2) Encontrar diversos eixos de simetria em determinadas figuras. } \\
\text { Completar figuras dados eixos de simetrias. } \\
\text { 3) Criar figuras simétricas a partir de dobraduras. } \\
\text { 4) Verificar se há simetria nas folhas de plantas. } \\
\text { 5) Verificar propriedades da simetria através do uso de espelhos. }\end{array}$ \\
\hline $\begin{array}{c}\text { Ornamentos } \\
\text { versus criatividade: uma alternativa } \\
\text { para ensinar geometria plana e } \\
\text { simetria (BIEMBENGUT; SILVA, } \\
\text { 1995) }\end{array}$ & $\begin{array}{l}\text { 1) Utilizar uma figura qualquer feita de um molde de cartolina } \\
\text { para trabalhar o conceito de translação. } \\
\text { 2) Utilizar papel dobrado e recortá-lo para trabalhar o conceito } \\
\text { de reflexão. } \\
\text { 3) Utilizar uma figura qualquer feita de um molde de cartolina } \\
\text { para trabalhar o conceito de rotação. Associar a reflexão e a } \\
\text { rotação para a formação de rosetas e a introdução do conceito de } \\
\text { simetria. } \\
\text { 4) Associar translações e reflexões. } \\
\text { 5) Construir mosaicos a partir das transformações geométricas. } \\
\text { 6) Realizar translações, construindo novas formas que } \\
\text { conservem a área da figura inicial. }\end{array}$ \\
\hline $\begin{array}{c}\text { Construindo o conceito de simetria } \\
\text { em relação a uma reta: do jardim de } \\
\text { infância ao } 3^{\circ} \text { grau (KALEFF, } \\
\text { 1999) }\end{array}$ & $\begin{array}{l}\text { 1) Jogo "queimada" através de um eixo de simetria, dobrando o } \\
\text { papel para atingir o jogador adversário. } \\
\text { 2) Jogar o mesmo jogo sem dobrar o papel, utilizando régua, } \\
\text { transferidor e esquadro, ou papel milimetrado. } \\
\text { 3) Utilizar o espelho para encontrar figuras simétricas. } \\
\text { 4) Formalizar o conceito de simetria e propor exercícios } \\
\text { teóricos. }\end{array}$ \\
\hline $\begin{array}{l}\text { O uso de espelhos e caleidoscópios } \\
\text { em atividades educacionais de } \\
\text { Geometria para } 7^{\mathrm{a}} \text { e } 8^{\mathrm{a}} \text { séries } \\
\text { (MURARI; PEREZ, 2002) }\end{array}$ & $\begin{array}{l}\text { 1) Verificar propriedades de reflexão através de uma malha } \\
\text { quadriculada. } \\
\text { 2) Explorar o eixo de simetria de figuras. } \\
\text { 3) Utilizar espelhos para encontrar figuras simétricas as } \\
\text { fornecidas. } \\
\text { 4) Verificar as figuras formadas através da utilização de dois ou } \\
\text { mais espelhos, paralelos ou não, e identificar as transformações } \\
\text { geométricas ocorridas. } \\
\text { 5) Obter diferentes polígonos através da utilização de um } \\
\text { conjunto de espelhos. } \\
\text { 6) Trabalhar pavimentações através do uso de materiais } \\
\text { manipuláveis e espelhos . }\end{array}$ \\
\hline $\begin{array}{l}\text { Exploração de trabalhos de Escher } \\
\text { em aulas de geometria (NINA; } \\
\text { MENEGASSI; SILVA, 2008) }\end{array}$ & $\begin{array}{l}\text { 1) Construir mosaicos a partir de polígonos regulares, inspirados } \\
\text { nos de Escher, através de rotações, translações e reflexões. } \\
\text { 2) Criar um módulo a partir de translações de partes de um } \\
\text { retângulo, e criar mosaicos a partir deles. } \\
\text { 3) Criar formas a partir de polígonos regulares com regiões } \\
\text { arredondadas, e criar mosaicos a partir delas. }\end{array}$ \\
\hline $\begin{array}{l}\text { Simetria no Ensino Fundamental } \\
\text { através da resolução de problemas: } \\
\text { possibilidades para um trabalho em }\end{array}$ & 1) Trabalhar o eixo de simetria através de dobras e recortes. \\
\hline
\end{tabular}




\begin{tabular}{|c|c|}
\hline $\begin{array}{l}\text { sala de aula (VIEIRA; PAULO; } \\
\text { ALLEVATO, 2013) }\end{array}$ & $\begin{array}{l}\text { 2) Escrever a palavra "resgate" de maneira que o motorista do } \\
\text { carro da frente possa lê-la em seu retrovisor. }\end{array}$ \\
\hline $\begin{array}{c}\text { A simetria nas aulas de matemática: } \\
\text { uma proposta investigativa } \\
\text { (LOPES; ALVES; FERREIRA, } \\
\text { 2015) }\end{array}$ & $\begin{array}{l}\text { 1) Criar figuras simétricas com o uso de papel carbono. } \\
\text { 2) Investigar eixos de simetria a partir de dobraduras no papel. } \\
\text { 3) Criar figuras simétricas a partir de coordenadas. } \\
\text { 4) Trocar as sequências com os colegas para que eles possam } \\
\text { construir as figuras desejadas. }\end{array}$ \\
\hline $\begin{array}{c}\text { Transformações isométricas com } \\
\text { manipulações em tela (ASSIS, } \\
\text { 2017) }\end{array}$ & $\begin{array}{l}\text { 1) Familiarizar-se com as ferramentas translação, rotação e } \\
\text { reflexão do software GeoGebra. } \\
\text { 2) Utilizar as ferramentas exploradas para deslocar uma figura } \\
\text { do } 1 .^{\circ} \text { para o } 3 .^{\circ} \text { quadrante do plano cartesiano, verificando que } \\
\text { transformações e caminhos podem ser utilizados para a } \\
\text { realização da tarefa. }\end{array}$ \\
\hline
\end{tabular}

A partir do Quadro 4, as tarefas foram analisadas segundo a classificação proposta por Ponte (2014) apresentada anteriormente, a fim de identificar quais delas se enquadravam como exercícios, problemas, explorações ou investigações. O Quadro 5 faz uma síntese das naturezas de tarefas que puderam ser observadas em cada um dos artigos. Para essa classificação, consideramos não só a tarefa em si, mas também a faixa etária para a qual ela é proposta, pois uma tarefa pode se enquadrar em uma ou outra classificação, dependendo do desenvolvimento cognitivo dos estudantes aos quais é aplicada. Este aspecto será discutido com maior profundidade posteriormente.

Quadro 5. Natureza das tarefas propostas nos artigos

\begin{tabular}{ccccc}
\hline Autor & Exercício & Problema & Exploração & Investigação \\
\hline $\begin{array}{c}\text { Fainguelernt e } \\
\text { Bordinhão (1990) }\end{array}$ & $\mathrm{X}$ & & & \\
\hline Kaleff (1994) & $\mathrm{X}$ & $\mathrm{X}$ & $\mathrm{X}$ & $\mathrm{X}$ \\
\hline $\begin{array}{c}\text { Biembengut e } \\
\text { Silva (1995) }\end{array}$ & $\mathrm{X}$ & & $\mathrm{X}$ & $\mathrm{X}$ \\
\hline Kaleff (1999) & $\mathrm{X}$ & $\mathrm{X}$ & $\mathrm{X}$ \\
\hline $\begin{array}{c}\text { Murari e Perez } \\
\text { (2002) }\end{array}$ & $\mathrm{X}$ & $\mathrm{X}$ & $\mathrm{X}$ \\
\hline $\begin{array}{c}\text { Nina, Menegassi } \\
\text { e Silva (2008) }\end{array}$ & & $\mathrm{X}$ & $\mathrm{X}$ \\
\hline $\begin{array}{c}\text { Vieira, Paulo e } \\
\text { Allevato (2013) }\end{array}$ & $\mathrm{X}$ & $\mathrm{X}$ & \\
\hline $\begin{array}{c}\text { Lopes, Alves e } \\
\text { Ferreira (2015) }\end{array}$ & & $\mathrm{X}$ & $\mathrm{X}$ & \\
\hline Assis (2017) & & Fonte: autores & & \\
\hline & & &
\end{tabular}

A seguir, traremos um exemplo, coletado dos artigos estudados, de cada um dos tipos de tarefa descritos anteriormente. 


\subsubsection{Exercício}

Dentre os artigos analisados, esta foi a natureza de tarefa mais identificada. É também o tipo mais frequente nos materiais didáticos, pois são exercícios simples, diretos e objetivos, que não demandam grandes desafios dos estudantes e possuem apenas uma possibilidade de resolução. Dos nove artigos analisados, sete possuíam tarefas com essas características: os trabalhos de Fainguelernt e Bordinhão (1990), Kaleff (1994), Biembengut e Silva (1995), Kaleff (1999), Murari e Perez (2002), Vieira, Paulo e Allevato (2013) e Assis (2017). Na maioria deles, esse tipo de tarefa é utilizado para introduzir um conceito com o qual os estudantes ainda não estão familiarizados, e em vários deles as tarefas são destinadas ao Ensino Fundamental, em especial aos Anos Iniciais, o que justifica sua escolha. Entretanto, os exercícios também podem ser utilizados para a apreensão de conceitos já estudados, como em Kaleff (1999). Isso não significa que outros tipos de tarefas não possam e não devam ser aplicados nesta etapa de ensino, para garantir que o estudante desenvolva plenamente todas as suas potencialidades de raciocínio. Ademais, o uso exclusivo desse tipo de tarefa pode não proporcionar uma aprendizagem significativa para o estudante.

A tarefa exposta a seguir, transcrita de Fainguelernt e Bordinhão (1990), pode ser considerada como um exemplo de exercício.

Figura 2. Tarefa - Exercício

Ex.: (1) a) Reproduza, por translação, no espaço ao lado a figura 1, obtendo a figura II:

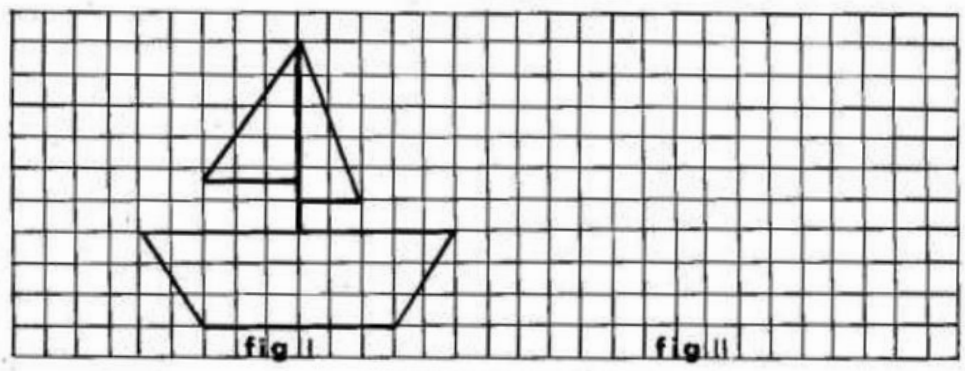

Fonte: FAINGUELERNT; BORDINHÃO, 1990, p. 52 
Todas as tarefas apresentadas por Fainguelernt e Bordinhão (1990) foram consideradas exercícios, pois, embora elas aumentem o grau de dificuldade, a proposta dos autores é que sejam trabalhadas durante todo o Ensino Fundamental e no Ensino Médio.

A tarefa transcrita na Figura 2, que apresenta uma única possibilidade de solução, não é a primeira tarefa proposta pelos autores e, segundo Fainguelernt e Bordinhão (1990), os estudantes já tiveram, em outros momentos da sua vida escolar, contato com os conceitos que ela demanda para a sua execução. Sendo assim, não deve proporcionar grandes desafios para a maioria dos estudantes. Com base nessas observações, pudemos considerar que se trata de um exercício.

\subsubsection{Problema}

Em contraste com os exercícios, embora os problemas sejam similares a eles, essa natureza de tarefa foi a menos recorrente nos artigos analisados, tendo sido observada em três deles. Os problemas, assim como os exercícios, não possuem mais de uma solução, porém demandam dos estudantes maiores desafios para serem solucionados. Dessa forma, normalmente considera-se que o estudante já tenha algum conhecimento sobre o conteúdo para realizar esse tipo de tarefa, como ocorre nos trabalhos de Kaleff (1994), Murari e Perez (2002) e Vieira, Paulo e Allevato (2013), em que os problemas aparecem após a introdução, por meio de exercícios, dos conceitos a serem estudados. O exemplo desse tipo de tarefa, apresentado a seguir, é de Vieira, Paulo e Allevato (2013) e consiste na segunda tarefa apresentada pelos autores, após o trabalho sobre o conceito de reflexão em uma tarefa prévia.

\section{Tarefa - Problema}

O Corpo de Bombeiros da cidade A renovou sua frota de ambulâncias. Para facilitar a identificação dos veículos nas ruas da cidade, o chefe da corporação pediu para que fosse pintada na parte frontal das ambulâncias a palavra RESGATE. Dessa forma, qualquer motorista poderia identificar o veículo oficial através do espelho retrovisor de seu carro. De que maneira a palavra RESGATE deve ser pintada nas ambulâncias para que o motorista do carro à frente consiga ler corretamente a palavra pintada através de seu espelho retrovisor?

Fonte: Vieira, Paulo e Allevato (2013, p. 625) 
Assim como na tarefa anterior, esta claramente apresenta apenas uma única possibilidade de resolução correta. No entanto, para a faixa etária para a qual ela é proposta (7. ${ }^{\circ}$ ano do Ensino Fundamental), sua execução demanda maiores desafios cognitivos. Portanto, ela foi considerada um problema.

\subsubsection{Exploração}

As tarefas exploratórias, embora não demandem dos estudantes grandes conhecimentos para serem solucionadas, permitem que eles busquem diferentes maneiras de solucioná-las. Tarefas com esse perfil foram identificadas em cinco artigos analisados: os de Biembengut e Silva (1995), Kaleff (1999), Murari e Perez (2002), Lopes, Alves e Ferreira (2015), e Assis (2017), e são propostas pelos autores como a aplicação e a validação de conceitos já apresentados. O exemplo a seguir, de Assis (2017), ilustra esse tipo de tarefa.

Figura 3. Tarefa - Exploração

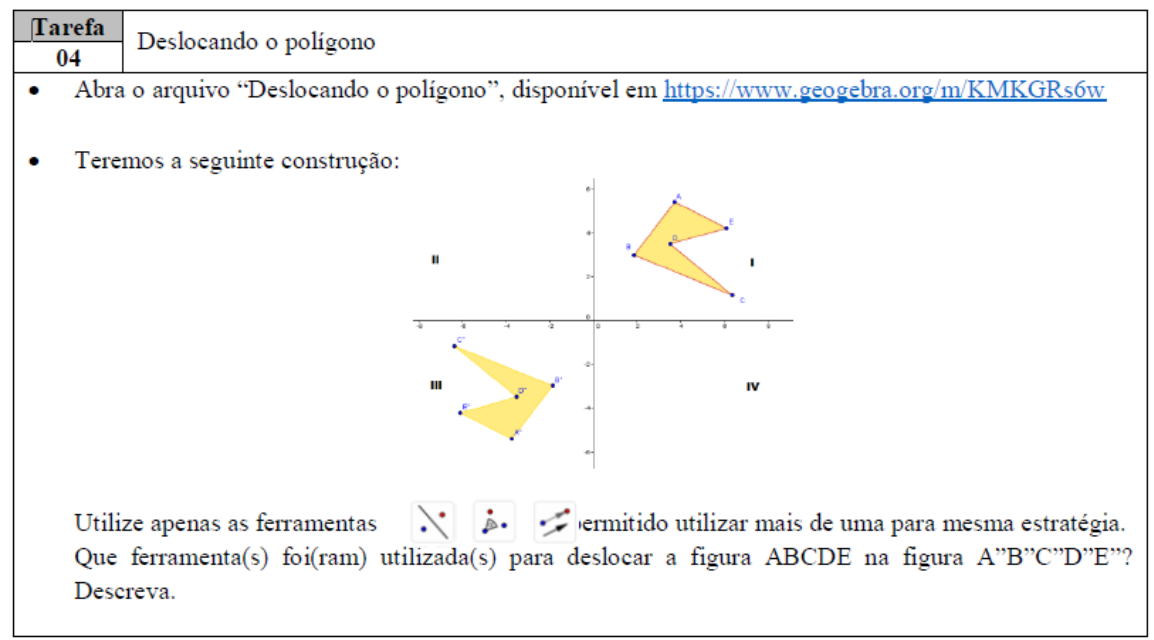

Fonte: ASSIS, 2017, p. 190

Embora a tarefa apresentada na Figura 3 apresente um único objetivo a ser atingido, o estudante pode utilizar-se de vários meios (ou 
seja, diferentes transformações geométricas) para chegar a ele. Portanto, por apresentar várias possibilidades, constitui-se em uma tarefa aberta. Não obstante, ela foi considerada de desafio reduzido para a faixa etária à qual é destinada ( $10^{\circ}$ ano do Ensino Médio), pelo fato de já terem sido trabalhadas previamente outras tarefas que abordaram as transformações necessárias para realizá-la. Assim, ela pode ser classificada como uma exploração.

\subsubsection{Investigação}

As tarefas investigativas são as de natureza considerada mais complexa, pois, além de demandarem do estudante um raciocínio elevado, podem apresentar diversas soluções, algumas vezes, inclusive, desconhecidas pelo professor. Por isso, essa natureza pode ser considerada bastante completa, e foi utilizada em seis dos nove artigos analisados: os de Kaleff (1994), Biembengut e Silva (1995), Kaleff (1999), Murari e Perez (2002), Nina, Menegassi e Silva (2008) e Lopes, Alves e Ferreira (2015). Dentre eles apenas Kaleff (1999) utiliza uma tarefa investigativa na introdução de um novo conteúdo. Nos demais artigos, este tipo de tarefa é empregado para consolidar e realizar a conclusão de um bloco temático.

Embora esse tipo de tarefa seja bastante completo, utilizá-la sempre na sala de aula pode ser tão ruim quanto utilizar apenas exercícios, pois, por demandarem muita dedicação dos estudantes, quando utilizadas em excesso podem desanimá-los. Ainda, tarefas investigativas ocupam um tempo longo para serem realizadas com êxito, o que, muitas vezes, não está disponível ao professor em sala de aula.

A complexidade dessas tarefas encontra-se na amplitude de fatores que elas abrangem, tanto na sua elaboração, para que tenham um caráter investigativo e atinjam os objetivos desejados pelo professor, quanto na resolução pelos estudantes, pois, embora devam propor desafios a eles, não podem ser extremamente difíceis, para não os desestimular. No entanto, a proposta desafiadora pode ter um enunciado aparentemente simples, como na tarefa proposta por Nina, Menegassi e Silva (2008), que será apresentada a seguir e evidencia a dificuldade de elaborar e trabalhar tarefas com esse perfil na sala de aula. 
Figura 4. Tarefa - Investigação

Atividade 1: Diante do estudo realizado acima, foi solicitado aos alunos que escolhessem uma das formas de polígonos (triângulo eqüilátero, quadrado ou hexágono) para cobrir um plano e a partir dela criar o seu modelo (módulo). A parte que é repetida chama-se módulo. $\mathrm{O}$ módulo se repete várias vezes até formar o mosaico. Os exemplos a seguir foram feitos por alguns alunos.

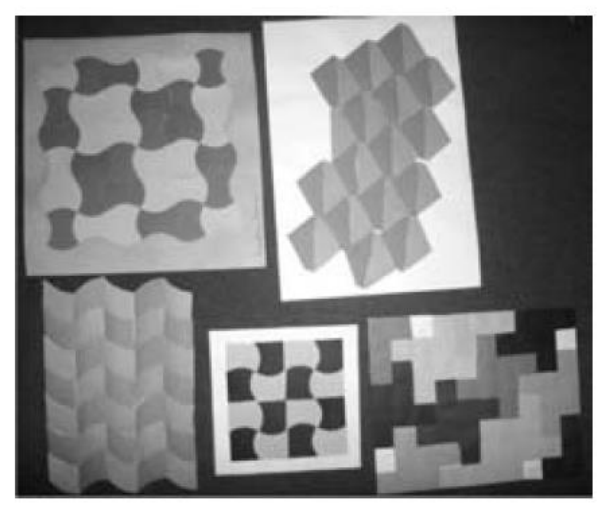

Fonte: NINA; MENEGASSI; SILVA, 2008, p. 128

Como é possível constatar na Figura 4, a tarefa proposta por Nina, Menegassi e Silva (2008) possui um enunciado simples e objetivo. No entanto, sua resolução apresenta inúmeras possibilidades, além de demandar certo esforço do estudante para ser solucionada. Essas características fizeram com que considerássemos essa tarefa como uma investigação.

Particularmente tratando dessa tarefa, podemos considerar que ela ainda pode trazer para o professor informações sobre o desenvolvimento cognitivo do estudante, o seu nível do seu conhecimento sobre as transformações geométricas, de acordo com a sua maior ou menor utilização na tarefa, e a sua criatividade. Assim, para potencializar a aprendizagem do estudante por meio do uso de tarefas investigativas, após sua aplicação, deve haver um momento de troca e discussão entre todos da sala, a fim de que possam tomar conhecimento das estratégias e das soluções desenvolvidas pelos colegas durante a execução da tarefa proposta, potencializando, dessa forma, a aprendizagem de todos. 


\section{Discussão dos resultados}

Este artigo abordou uma síntese da literatura, baseando-se em duas questões norteadoras: (i) Que perfil apresentam as pesquisas em Educação Matemática que tratam da prática do professor? e (ii) Qual a natureza das tarefas elaboradas para abordar as transformações geométricas na prática em sala de aula?

Para (i), evidenciamos que os artigos analisados apresentam dados empíricos e são resultados de pesquisas, e não de relatos de experiência. O perfil das pesquisas indicou a formação continuada, a formação inicial e os conhecimentos do professor como focos de análise. Em termos de referenciais teóricos discutidos no âmbito dos artigos, destacam-se aqueles vinculados ao conhecimento matemático para o ensino, ao uso de tecnologias digitais, em particular, à geometria dinâmica, assim como aos referenciais vinculados à didática francesa.

Para (ii), constatamos que a natureza das tarefas presentes nos artigos que tratam das transformações geométricas foi diversa, sendo observados exercícios, problemas, explorações e investigações. Ainda, destacamos que apenas dois artigos (FAINGUELERNT; BORDINHÃO, 1990; NINA; MENEGASSI; SILVA, 2008) apresentaram apenas um tipo de tarefa, mostrando que cada uma dessas naturezas possui uma determinada característica e relevância. Assim, entendemos que todas as naturezas das tarefas devem ser utilizadas em sala de aula de maneira diversa, a fim de ampliar a possibilidade de construção de conhecimentos por parte dos estudantes, de acordo com os propósitos do professor. Utilizar estritamente uma natureza de tarefa, seja ela qual for, para todos os processos de aprendizagem, pode não oportunizar as diferentes formas de construção do conhecimento, tanto para os professores, quanto para os estudantes.

As tarefas classificadas como exercícios prevaleceram, sendo observadas em sete dos nove artigos que compuseram essa etapa da síntese da literatura. Em seguida, foram observadas com maior frequência as investigações. Posteriormente, vieram as explorações, presentes em cinco artigos, e por fim, os problemas, observados em apenas três dos nove artigos. Esse aspecto pode revelar ser mais conveniente aliar um desafio reduzido a uma tarefa fechada e, a uma tarefa aberta, vincular um desafio elevado (exercícios e investigações), em vez de mesclar essas características (problemas e explorações). 
Outro aspecto a ser apontado com relação às tarefas analisadas diz respeito às principais aplicações observadas nos artigos, para cada uma das naturezas das tarefas. $\mathrm{Na}$ maioria dos estudos analisados, os exercícios foram utilizados como tarefas introdutórias de um conteúdo, o que é compreensível, por serem tarefas mais simples. Outro uso frequentemente associado a essa natureza de tarefa é a apreensão de conteúdos, o que ocorreu em apenas um dos artigos. As tarefas alocadas nas demais naturezas de pesquisa possuíam como objetivo aprofundar e consolidar conceitos já introduzidos, em geral, aumentando a complexidade e a possibilidade de resolução das tarefas, na medida em que os estudantes apresentavam apropriação dos conceitos desejados.

Ainda, foi possível constatar que algumas das tarefas propostas eram similares. A partir disso, podem ser tomadas duas conclusões: são tarefas tradicionais e eficazes para o ensino das transformações geométricas, já consolidadas nos estudos acerca do tema; há carência de novas tarefas, mais adequadas ao contexto atual dos estudantes, voltadas para o ensino das transformações geométricas.

\section{Considerações finais e perspectivas futuras}

Umas das temáticas de pesquisa mais recorrentes na Educação Matemática diz respeito à pratica do professor. Essa recorrência pode ser resultante de lacunas existentes nos cursos de licenciatura, com relação aos mais variados conteúdos matemáticos, já que não é possível abordá-los com a devida profundidade durante o período da formação inicial. Dessa maneira, cabe ao professor a proatividade de buscar processos de formação continuada nas áreas em que ele constatar maior necessidade. Com efeito, discussões vêm sendo realizadas nesse âmbito, buscando suprir essas lacunas que dizem respeito ao conhecimento do professor, tanto na formação inicial quanto na formação continuada.

Um dos conteúdos matemáticos que se enquadra nessa situação é o de transformações geométricas. Esta síntese da literatura pôde corroborar as carências dos professores acerca desse conteúdo, bem como mostrar que a utilização de ferramentas adequadas pode minimizar as lacunas observadas com relação ao seu ensino. Uma dessas ferramentas são as tarefas. Logo, o professor necessita ter, 
primeiramente, domínio do conteúdo matemático, para posteriormente selecionar uma tarefa de determinada natureza, para contribuir para a apreensão desse conteúdo.

Classificar as tarefas de acordo com a sua natureza não é um trabalho fácil, pois alguns aspectos podem estar evidentes, mas outros podem ser interpretados de maneiras diferentes por quem analisa a tarefa, o que acarretaria classificações distintas das aqui apresentadas. Ainda, as tarefas podem ser fechadas ou abertas, dependendo de como ela é apresentada para o estudante, e também podem proporcionar desafios elevados ou reduzidos, em função da faixa etária para a qual é aplicada. Assim, para o professor é fundamental possuir familiaridade com uma determinada tarefa, a ponto de identificar se ela pode ou não cumprir os objetivos desejados. E, em caso negativo, deve possuir artefatos para que ele possa realizar as adequações necessárias.

Também pode ser positivo, tanto para os estudantes quanto para os professores, utilizar tarefas para outros propósitos além dos observados nesta síntese da literatura, como, por exemplo, adotar explorações e investigações para introduzir novos conteúdos. Embora cada natureza de tarefa possa ser mais direcionada a uma determinada fase do processo de aprendizagem, essa ação pode modificar a rotina da sala de aula e despertar um maior interesse dos estudantes.

Portanto, este estudo pretende ter continuidade, por meio de processos de formação continuada de professores, consolidando os conceitos de transformações geométricas e fornecendo ferramentas para que os docentes possam identificar - e transitar entre eles - os aspectos aqui discutidos com relação às tarefas. Ainda, se as tarefas disponíveis não suprirem a demanda desses professores, importa que eles sejam capazes de elaborar novas tarefas, das mais diversas naturezas, adequadas aos seus objetivos, com a finalidade de potencializar a aprendizagem dos estudantes acerca desse conteúdo matemático.

Recebido em: 28/11/2019

Aprovado em: 19/04/2020 


\section{Referências}

(os artigos indicados com “*” compuseram a revisão de literatura)

*ASSIS, A. R. Transformações isométricas com manipulações em tela. Boletim GEPEM. Seropédica (RJ), n. 70, p. 186-197, jan./jun. 2017.

*BIEMBENGUT, M. S.; SILVA, V. C. Ornamentos versus criatividade: uma alternativa para ensinar geometria plana e simetria. Educação Matemática em Revista, Brasília, n. 4, p. 39-44, 1995.

DELMONDI, N. N.; PAZUCH, V. Um panorama teórico das tendências de pesquisa sobre o ensino de transformações geométricas. Revista Brasileira de Estudos Pedagógicos, Brasília, v. 99, n. 253, p. 659686, set./dez. 2018.

. O ensino de transformações geométricas: uma análise dos cadernos do aluno e do professor do estado de São Paulo. Revista Educação Matemática - ReMat, São Paulo, v. 16, n. 22, p. 210-231, maio/ago. 2019.

*FAINGUELERNT, E. K.; BORDINHÃO, N. C. Transações e simetrias no plano. Boletim GEPEM, Seropédica (RJ), n. 27, p. 49-62, 1990.

FIORENTINI, D.; LORENZATO, S. Investigação em educação matemática: percursos teóricos e metodológicos. Campinas, SP: Autores Associados, 2006.

*KALEFF, A. M. M. R. Uma aplicação do conceito de simetria axial plana visando a um ensino interdisciplinar. Zetetiké, Campinas, n. 2, p. 8591, 1994.

Construindo o conceito de simetria em relação a uma reta: do jardim de infância ao $3^{\circ}$ grau. Boletim GEPEM, Seropédica (RJ), n. 35, p. 42-56, 1999.

*LIMA, I. Conhecimentos e concepções de professores de matemática: análise de sequências didáticas. Educação Matemática Pesquisa, São Paulo, v. 13, n. 2, p. 359-385, 2011.

*LOPES, L. S.; ALVES, G. L. P.; FERREIRA, A. L. A. A simetria nas aulas de matemática: uma proposta investigativa. Educação e Realidade, Porto Alegre, v. 40, n. 2, p. 549-572, abr./jun. 2015. 
MAIA, C. M. F. As isometrias na inovação curricular e a formação de professores de Matemática do Ensino Básico. 2014. 332 f. Tese (Doutorado) - Departamento de Ciências da Educação e do Património, Universidade Portucalense, Porto, Portugal, 2014.

*MURARI, C.; PEREZ, G. O uso de espelhos e caleidoscópios em atividades educacionais de geometria para $7^{\mathrm{a}}$ e $8^{\mathrm{a}}$ séries. Bolema, Rio Claro (SP), v. 15, n. 18, p. 1-25, set. 2002.

NG, O. L.; SINCLAIR, N. Young children reasoning about symmetry in a dynamic geometry environment. ZDM, Hamburgo, v. 47, n. 3, p. 421434, 2015.

*NINA, C. T. D.; MENEGASSI, M. E. J.; SILVA, M. M. Exploração de trabalhos de Escher em aulas de geometria. Boletim GEPEM, Seropédica (RJ), n. 53, p. 111-132, jul./dez. 2008.

*OLIVEIRA, G. P.; LIMA, N. S. M. Estratégias didáticas na formação continuada de professores de Matemática: uma investigação sobre homotetia. Educação Matemática Pesquisa, São Paulo, v. 20, n.1, p. 385-418, 2018.

PAZUCH, V.; RIBEIRO, A. J. Conhecimento profissional de professores de matemática e o conceito de função: uma revisão de literatura. Educação Matemática Pesquisa, São Paulo, v. 19, n. 1, p. 465-496, 2017.

PONTE, J. P. da. Tarefas no ensino e na aprendizagem da Matemática. In: PONTE, J. P. da (Org.). Práticas profissionais dos professores de Matemática. Lisboa: Universidade de Lisboa, 2014.

*SANTOS, M. R.; BICUDO, M. A. V. Uma experiência de formação continuada com professores de Arte e Matemática no ensino de geometria. Bolema, Rio Claro (SP), v. 29, n. 53, p. 1329-1347, dez. 2015.

*SILVA, C. V.; ALMOULOUD, S. A. Uma articulação entre o quadro dos paradigmas geométricos e a Teoria das Situações Didáticas. Acta Scientiae, Canoas, v. 20, n. 1, p. 111-129, jan./fev. 2018.

*SILVA, G. H. G.; PENTEADO, M. G. Geometria dinâmica na sala de aula: o desenvolvimento do futuro professor de matemática diante da imprevisibilidade. Ciência e Educação, Bauru, v. 19, n. 2, p. 279-292, 2013.

*TURGUT, M.; YENILMEZ, K.; ANAPA, P. Symmetry and rotation skills of prospective elementary Mathematics teachers'. Bolema, Rio Claro (SP), v. 28, n. 48, p. 383-402, abr. 2014. 
*VIEIRA, G.; PAULO, R. M.; ALLEVATO, N. S. G. Simetria no ensino fundamental através da resolução de problemas: possibilidades para um trabalho em sala de aula. Bolema, Rio Claro (SP), v. 27, n. 46, p. 613-630, ago. 2013.

*VISEU, F.; MENEZES, L.; ALMEIDA, J. Conhecimento de geometria e perspectivas de professores do $1 .^{\circ}$ ciclo do ensino básico sobre seu ensino. REVEMAT, Florianópolis (SC), v. 08, n. 1, p. 156-178, 2013.

WAGNER, E. Construções geométricas. 6. ed. Rio de Janeiro: SBM, 2007. 